\title{
IRRATIONAL BELIEFS AND THE ANXIETY DISORDERS
}

\author{
Joseph A. Himle \\ The University of Michigan Hospitals \\ Ann Arbor \\ David P. Himle \\ The University of Michigan \\ Ann Arbor \\ Bruce A. Thyer \\ University of Georgia \\ Athens
}

\begin{abstract}
This study investigated the levels of irrationality reported by a clinical sample of anxiety disorder patients, including simple and social phobics, panic disorder patients, agoraphobics, and obssessive compulsive patients. The levels of irrationality were compared between these groups and a group of normal control subjects, using the Rational Behavior Inventory (RBI). Agoraphobic patients were significantly less rational than control subjects on six of the RBI's subfactors and the total score of the Inventory. Patients in all diagnostic categories except simple phobia were significantly different from control subjects on the projected misfortune subfactor, and patients in all categories except simple phobia and panic disorder were significantly different from controls on the total RBI score. There were only four instances where patients in anxiety disorder categories significantly differed from each other in levels of irrationality. The implications of these findings, methodological limitations, and directions for future research are discussed.
\end{abstract}

\footnotetext{
Joseph A. Himle, ACSW is a Clinical Social Worker at the Anxiety Disorders Program, Department of Psychiatry, University of Michigan. David P. Himle, Ph.D. is an Associate Professor of Social Work at the University of Michigan. Bruce A. Thyer, Ph.D. is an Associate Professor of Social Work, University of Georgia and Faculty Fellow at the University Affiliated Program. He is also an Associate Clinical Professor at the Department of Psychiatry and Health Behavior, Medical College of Georgia.

Send requests for reprints to Joseph A. Himle, Department of Psychiatry, University of Michigan Hospitals, Ann Arbor, MI 48109-08400.
} 
The current use of cognitive-behavioral treatment techniques relies upon the theory that many psychiatric disorders, including pathological anxiety, are caused or maintained by irrational beliefs (Ellis \& Grieger, 1977; Beck \& Emery, 1985). This theory has been partially supported by several correlational studies with analogue samples, which have demonstrated that irrational beliefs are associated with certain types of psychiatric symptomatology, such as state anxiety phobic anxiety, obsessive - compulsiveness, depression and psychoticism (Himle, Thyer, and Papsdorf, 1982; Thyer, Papsdorf, and Kilgore, 1983).

A few studies have also demonstrated that irrational beliefs are also present among clinical patients exhibiting particular types of phobic anxiety. Sutton-Simon and Goldfried (1979) have reported statistically significant, though modest correlations between irrational beliefs, as measured by the Irrational Beliefs Test, and social anxiety as measured by the Social Avoidance and Distress Scale, and also between irrational beliefs and acrophobia as measured by the Fear of Heights Survey. Thyer, Papsdorf and Kramer (1983) reported that irrational thinking as measured by the Rational Behavior Inventory was significantly correlated, though minimally, with general phobic anxiety as measured by the Fear Survey Schedule. They attributed the minimal association with phobic anxiety to the fact that most of their subjects attributed their phobias to experiences which were best explained by classical conditioning factors, rather than by cognitive distortions. Mizes, Landolf-Frische, and Grossman-McKee (1987) also reported significant correlations between rationality scores, as measured by the Rational Behavior Inventory and the Irrational Beliefs Test, and scores on the Fear Questionnaire among patient groups of simple phobics, and agoraphobics.

In addition, some studies have presented clinical and anecdotal observations which suggest that anxious patients report self-statements similar to Ellis' (1973) categorization of irrational beliefs. For example, Beech and Vaughan (1978) reported that phobic and obsessional patients have serious difficulty making decisions and a predisposition to avoid life's problems. Reed (1985) stated that obsessional patients had an excessive fear of losing self-control, conformed in an excessive manner to social prescriptions for proper conduct, and were the ultimate perfectionists. Beck and Emery (1985) stated that the fear of loss of emotional control was characteristic of patients exhibiting panic attacks. They described social phobics as individuals who had an excessive fear of being evaluated by others, and who experienced shame 
and fear of abandonment because of personal mistakes and failures in life. In addition, it has been suggested by Sutton-Simon and Goldfried (1979) that social anxiety has a larger cognitive component than acrophobia, because social anxiety involves implicit cognitive concerns with the evaluation of others, while acrophobia may be related to conditioned anxiety responses accompanied by minimal cognitive distortion.

In spite of this evidence, a number of authors have suggested that further replications of the nature of irrational beliefs among clinical samples are needed, that the validity of the Rational Behavior Inventory needs to be established for specific classes of anxiety disorders, and that research is lacking into the specific irrational beliefs among obsessive-compulsives (Martzke, Andersen, \& Cacioppo, 1987; Emmelkamp, 1987). Therefore, to further examine and clarify the relationship between various types of anxiety disorders and irrational thinking, this present study reports the results of an assessment of the levels of irrationality between groups of clinically anxious patients, as categorized by the use of DSM-III criteria (American Psychiatric Association, 1980), and a group of normal controls.

\section{METHOD}

\section{Subjects}

The research participants were 65 psychiatric outpatients who met the DSM-III diagnostic criteria for either simple phobia $(N=13)$, social phobia $(\mathrm{N}=10)$, panic disorder $(\mathrm{N}=10)$, agoraphobia with panic attacks $(\mathrm{N}=22)$, obsessive-compulsive disorder $(\mathrm{N}=10)$, and a group of normal controls $(\mathrm{N}=44)$. Each patient had sought treatment at the Anxiety Disorders Program of the Department of Psychiatry at the University of Michigan Hospitals, and was given a diagnosis by a clinician skilled in the use of DSM-III criteria. The reliability of the assessment of anxiety disorder diagnostic categories among mental health professionals has been examined, and the results have indicated an acceptable level of interrater reliability in the assessment of such disorders (American Psychiatric Association, 1980).

The clinical sample was composed of 22 men and 43 women with a mean age of 35.12 years. The average age of onset of the anxiety disorder was 23 years. The control group was composed of 8 male and 36 female graduate students with a mean age of 35.73 years. 


\section{Procedure}

Each patient was asked to complete the Rational Behavior Inventory (Shorkey \& Whiteman, 1977) as part of the clinic's routine assessment protocol. The psychometric properties of the Ratonal Behavior Inventory (RBI) are robust, including discriminant validity (Smith \& Zurawski, 1983), convergent validity (Smith, Boaz, \& Denny, 1984; Himle, Thyer, \& Papsdorf, 1982), factor structure (Himle, Hnat, Thyer \& Papsdorf, 1985), test-retest reliability (Thyer, Papsdorf \& Neal, 1983), and normative data (Thyer, Papsdorf, Himle, \& Bray, 1981).

The RBI consists of a 37 item questionnaire which yields a total irrationality score as well as 11 subscores, each approximately corresponding to one of the major irrational beliefs outlined in the rationalemotive therapy literature (Ellis, 1973; Ellis \& Harper, 1975). Factor 1 (catastrophizing) is a measure of the tendency for individuals to escalate the seriousness of possible future misfortune; factor 2 (guilt) refers to guilt experienced for deviations from social norms; factor 3 (perfectionism) represents the demand for perfection in all areas of behavior; factor 4 (approval) represents the rationality of the frame of reference from which an individual makes value judgments about his/ her attributes, ideas and behavior; factor 5 (caring and helping) reveals the degree to which it is demanded that all people care for and help one another; factor 6 (blame and punishment) measures the degree of blame and punishment of self and others; factor 7 (inertia and avoidance) indicates the individual's ability to counteract avoidance tendencies by accepting difficulties and working on unpleasant tasks; factor 8 (independence) evaluates the acceptance of independence in decision making and the consequences of actions; factor 9 (self-downing) refers to the tendency to upset oneself by negative self-evaluations; factor 10 (projected misfortune) measures the tendency to which the individual is upset by possible future misfortunes, irrespective of the probability of their occurrence; and factor 11 (control of emotions), measures the belief that one has self-control over emotions. The overall index of rationality ranges from a score of 0 to a score of 38 , with higher scores indicating greater rationality.

\section{RESULTS}

The mean age and gender distributions of the anxiety patients and the control group were not statistically significantly different. The 
mean total RBI score for the anxious patients was 21.4, and 28.3 for the normal subjects, which was significantly different $[t(107)=$ $-6.43, p<.001]$, indicative of higher levels of irrational beliefs among the anxious patients. The mean score levels of irrationality between the different types of anxiety diagnoses were examined using post-hoc Scheffe group comparisons (Hays, 1963) for each RBI factor and the total RBI score. The results are presented in Table 1.

Significant differences in mean scores were found between agoraphobics and control subjects on factor 1 (catastrophizing), factor 6 (blame and punishment), factor 7 (inertia and avoidance), factor 8 (independence), factor 9 (self-downing), factor 10 (projected misfortune), factor 11 (control of emotions), and the total RBI score. In all of these instances agoraphobics reported significantly lower rationality than control subjects. Agoraphobics also had significantly lower rationality scores than simple phobics on factor 9 (self-downing), on factor 10 (projected misfortune), and the total RBI score. Obsessive compulsive patients had significantly lower rationality scores than the control subjects on factor 10 (projected misfortune) and the total RBI score, and lower rationality scores than simple phobics on factor 10 (projected misfortune). Social phobic patients had significantly lower rationality scores than control subjects on factor 4 (approval), factor 10 (projected misfortune), the total RBI score and higher rationality scores than agoraphobics on factor 8 (independence). Patients with panic disorder had significantly lower rationality scores on factor 10 (projected misfortune) than the control subjects. No other significant differences were found between mean scores among diagnostic groups, or between the diagnostic groups and the control group.

\section{DISCUSSION}

Since only five statistically significant differences in rationality mean scores were found between groups of patients in the various DSM-III categories, these data suggest that unique differences between types of irrational thinking and specific anxiety disorder categories are not prominent features among this sample of severely anxious patients. This finding and the lack of significant differences in irrationality between a number of phobic groups (simple phobia and panic disorder) and the control group on ten of the eleven irrationality subfactors lends some support to the contention of Wolpe (1981) and 


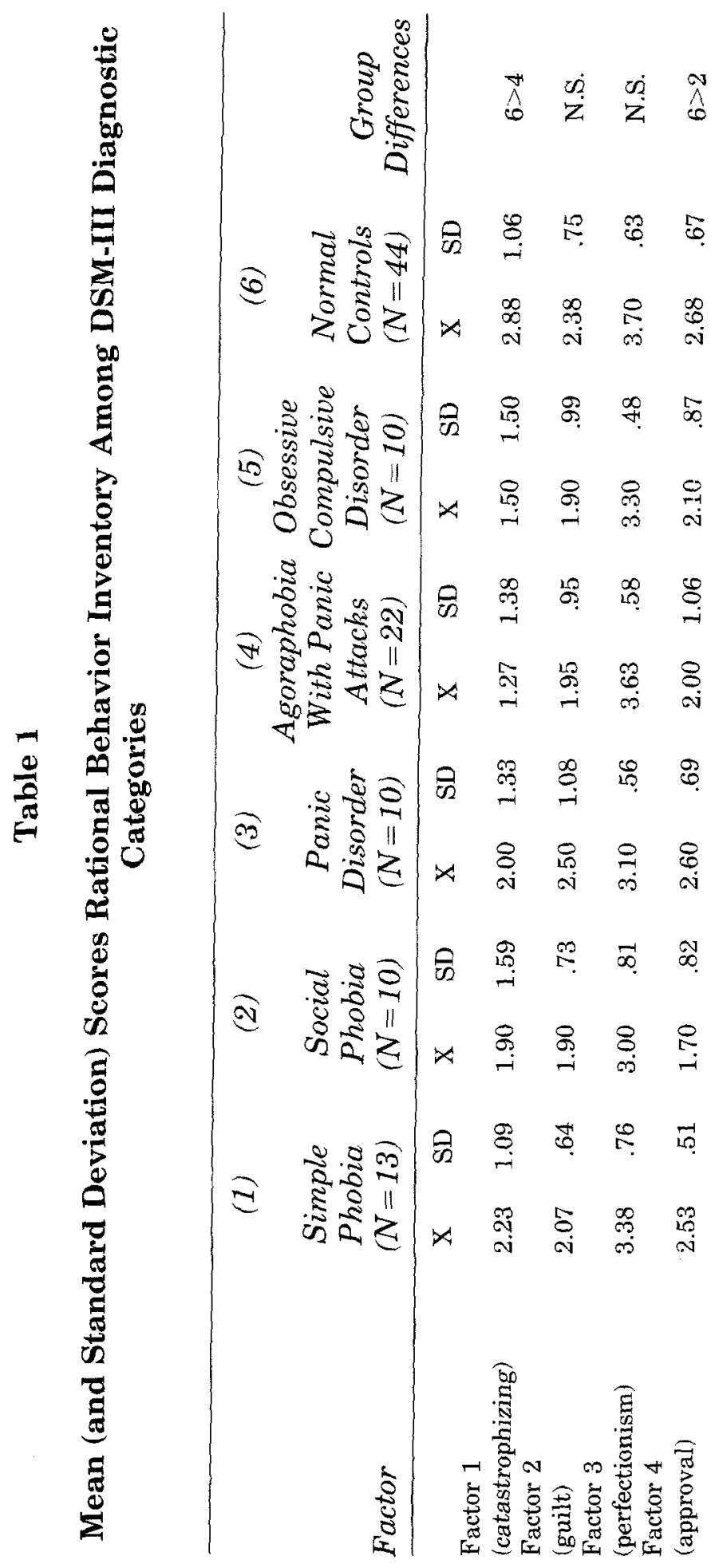




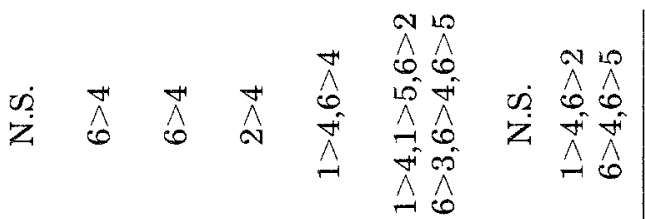

$$
\begin{aligned}
& \text { ๑ }
\end{aligned}
$$

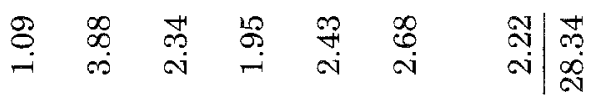

$$
\begin{aligned}
& \text { 冓 }
\end{aligned}
$$

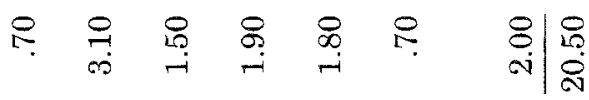

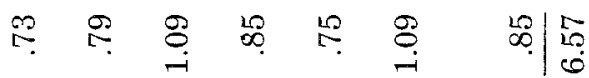

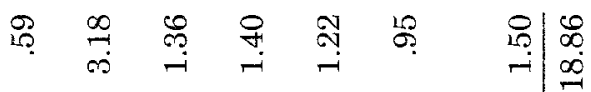

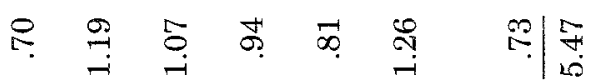

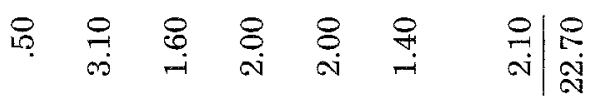

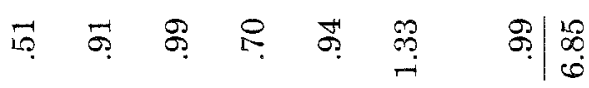

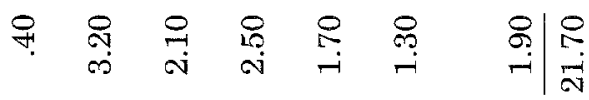

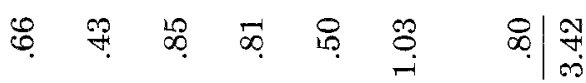

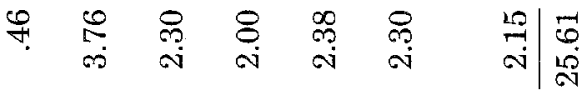

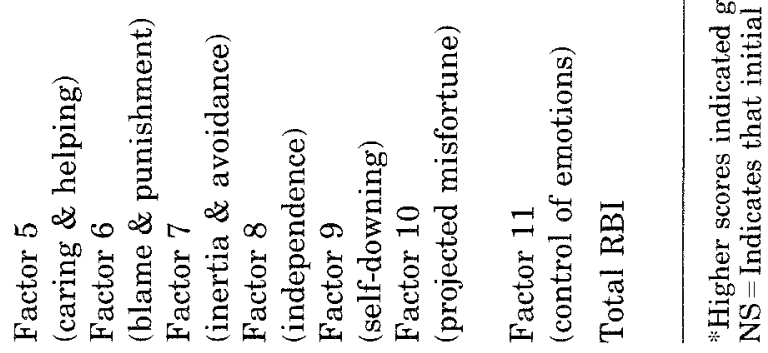


Ost and Hugdahl (1981) that phobic anxiety may be caused by reflexive conditioning factors rather than by cognitive distortion.

However, there are a number of exceptions to this contention. For example, agoraphobics reported significantly lower levels of rationality than control subjects on six factors (catastrophizing, need for approval, blame and punishment, independence, self-downing, and projected misfortune) and the total RBI score. A number of authors have commented on the rather complex nature of agoraphobia. Fisher and Wilson (1985) found that agoraphobics consistently overrated their anxiety and physiological arousal, and rated themselves as more responsible for their failure to cope with their fears than nonagoraphobics (self-downing?), and as responsible for fearful or negative events (blame and punishment?), and experienced more anxiety than they believed others would in anxious situations (catastrophizing?). In a review of the treatment approaches to agoraphobia, Jansson and Ost (1982) reported factor analytic evidence and clinical observations, which suggested that agoraphobics may have a broader range of neurotic symptoms, such as depression, hysteria, hypochondriasis, and depersonalization than other phobic disorders. They suggested that agoraphobia may not be strictly considered as a phobic response, but rather a clinical syndrome with a variety of neurotic problems.

In this study, agoraphobics reported a greater tendency to be upset by the possibility of future misfortune than control subjects. This may be due to the particular nature of the fears associated with agoraphobia. Hallam and Hafner (1978) found that agoraphobics reported a distinct cluster of fears associated with public places, shopping, and travel in contrast to simple phobics. One can hypothesize that the social pressure to expose oneself to these places and activities, rather than avoid them, may account for such fear of possible misfortune.

However, since agoraphobia may be effectively treated by exposure therapy, which usually does not involve a cognitive restructuring component (Zitrin, Klein, \& Woerner, 1980; Jansson \& Ost, 1982), and has been found to more successful than cognitive therapy procedures in treating agoraphobia (Emmelkamp, Kuipers, \& Eggeraat, 1978; Emmelkamp \& Marsh, 1982), it is not certain as to the role such irrational beliefs play in the assessment and treatment of this disorder. This issue needs to be reexamined.

It is of interest that panic disorder patients without agoraphobia reported significantly lower rationality on only one factor (projected misfortune), which lends some support to the general contention that spontaneous panic attacks may have a biochemical etiology (Thyer, 1987). Further research is needed to examine this issue. 
It important to note that there was a significantly lower level of rationality between patients in all anxiety disorder categories, except simple phobia, and control group subjects related to projected misfortune (factor 10)). This may be due to the learning history of anxious patients, who have experienced a number of unpleasant and unplanned contacts with phobic stimuli over time, and may have learned to dread them, and exaggerate the probability of their occurrence. This possibility needs to be examined as part of the general research question as to the exact nature of cognitive distortions in the development of anxiety disorders (Thyer, Westhuis, \& Harrison, 1987).

The finding that there were no significant differences among subjects in the anxiety categories, and between subjects in these categories and control subjects on the factor related to control of emotions (factor 11), is unusual. This is contrary to the hypothesis of Beck and Emery (1985) who contend that the fear of loss of emotional control was characteristic of a number of types of anxiety, including panic disorder. In addition, Barlow and Cerny (1988) have described a method of treatment for panic disorders which utilizes procedures designed to help such patients increase their ability to control their emotions. Further research needs to be directed to examine the role of the fear of loss of emotional control among patients experiencing various types of anxiety disorders.

Based upon the data reported from this sample, it is important to emphasize that different aspects of irrationality were not directly related to different categories of anxiety in the majority of instances. The exceptions were the reports of agoraphobic patients, and in one instance, social phobics. Therefore, the assumption that different phobic disorders have a unique constellation of irrational beliefs relevant to that category, may be untenable. However due to the relatively small size of our sample, replications of this study are needed to examine this issue.

In summary, this study has demonstrated that among a group of patients, classified according to DSM-III anxiety disorder criteria, and a group of control subjects, few significant differences between mean scores of rationality were observed, except for agoraphobics. Further research needs to be done to examine the occurrence of irrational beliefs among other clinical samples of anxiety disorder patients. Such research will assist in the appropriate selection of intervention procedures, which are responsive to the presence or absence of irrational thinking among such anxious patients. 


\section{REFERENCES}

American Psychiatric Association (1980). Diagnostic and statistical manual of mental disorders (3rd ed.). Washington, DC: American Psychiatric Association.

Barlow, D. H., \& Cerny, J. (1988). Psychological treatment of panic. New York: Guilford.

Beck, A. T., \& Emery, G. (1985). Anxiety disorders and phobias. New York: Basic Books.

Beech, H. R., \& Vaughan, M. (1978). Behavioral treatment of obsessional states. New York: Wiley.

Ellis, A. (1973). Humanistic psychotherapy. New York: McGraw-Hill.

Ellis, A., \& Grieger, R. (1977). Handbook of rational-emotive therapy. New York: Springer.

Ellis, A., \& Harper, R. A. (1975). A new guide to rational living. North Hollywood, CA: Wilshire.

Emmelkamp, P. M. (1987). Obsessive-compulsive disorders. In L. Michelson \& L. Michael Ascher (Eds.), Anxiety and stress disorders: Cognitive-behavioral assessment and treatment (pp. 310-331). New York: Guilford.

Emmelkamp, P. M. G., \& Marsh, P. P. (1982). Cognition and exposure in vivo in the treatment of agoraphobia: Short-term and delayed effects. Cognitive Therapy and Research, 6, 77-88.

Emmelkamp, P. M. G., Kuipers, A. C. M., \& Eggeraat, J. B. (1978). Cognitive modification versus prolonged exposure in vivo: A comparison with agoraphobics as subjects. Behaviour Research and Therapy, 16, 33-41.

Fisher, L. M., \& Wilson, G. T. (1985). A study of the psychology of agoraphobia. Behaviour Research and Therapy, 23, 97-107.

Hallam, R. S., \& Hafner, R. J. (1978). Fears of phobic patients: Factor analyses of self-report data. Behaviour Research and Therapy, 16, 1-6.

Hays, W. L. (1963). Statistics for psychologists. New York: Holt, Rinehart and Winston.

Himle, D. P., Thyer, B. A., \& Papsdorf, J. D. (1982). Relationship between rational beliefs and anxiety. Cognitive Therapy and Research, 6, 219-223.

Himle, D. P., Hnat, S., Thyer, B. A., \& Papsdorf, J. P. (1982). Factor structure of the Rational Behavior Inventory. Journal of Clinical Psychology, 41, 368-371.

Jansson, L., \& Ost, L. (1982). Behavioral treatments for agoraphobics: An evaluative review. Clinical Psychology Review, 2, 311-336.

Martzke, J. S., Andersen, B. L., \& Cacioppo, J. T. (1987). Cognitive assessment of anxiety disorders. In L. Michelson \& L. M. Ascher (Eds.), Anxiety and stress disorders: Cognitive-behavioral assessment and treatment (pp. 62-88). New York: Guilford.

Mizes, J. S., Landolf-Firsche, B., \& Grossman-McKee, D. (1987). Patterns of distorted cognitions in phobic disorders: An investigation of clinically severe simple phobics, social phobics, and agoraphobics. Cognitive Therapy and Research, 11, 583-592.

Ost, L., \& Hugdahl, K. (1981). Acquisition of phobias and anxiety response patterns in clinical patients. Behaviour Research and Therapy, 19, 439-447. 
Reed, G. F. (1985). Obsessional experience and compulsive behavior: A cognitive-structural approach. New York: Academic Press.

Shorkey, C., \& Whiteman, V. (1977). Development of the rational behavior inventory. Educational and Psychological Measurement, 37, 527-533.

Smith, T. W., \& Zurawski, R. M. (1983). Assessment of irrational beliefs: The question of discriminant validity. Journal of Clinical Psychology, 39, 976-979.

Smith, T. W., Boaz, T. L., \& Denny, D. R. (1984). Endorsement of irrational beliefs as a moderator of the effects of stressful life events. Cognitive Therapy and Research, 8, 363-370.

Sutton-Simon, K., \& Goldfried, M. R. (1979). Faulty thinking patterns in two types of anxiety. Cognitive Therapy and Research, 3, 193-203.

Thyer, B. A. (1987). Treating anxiety disorders. Newbury Park, CA: Sage.

Thyer, B. A., Papsdorf, J. D., \& Kilgore, S. A. (1983). Relationships between irrational thinking and psychiatric symptomatology. Journal of Psychology, 113, 31-34.

Thyer, B. A., Papsdorf, J. D., \& Kramer, M. K. (1983). Phobic anxiety and irrational belief systems. Journal of Psychology, 114, 145-149.

Thyer, B. A., Papsdorf, J. P., \& Neal, L. (1983). Cognitive belief systems and their persistence: Test-retest reliability of the Rational Behavior Inventory. Psychological Reports, 53, 915-918.

Thyer, B. A., Westhuis, D., \& Harrison, D. F. (1987). Irrational beliefs and phobic anxiety: A controlled clinical replication and a cautionary note. Journal of Anxiety Disorders, 1, 249-256.

Thyer, B. A., Papsdorf, J. P., Himle, D., \& Bray, H. (1981). Normative data on the Rational Behavior Inventory. Educational and Psychological Measurement, 41, 757-760.

Wolpe, J. (1981). The dichotomy between classical conditioning and cognitively learned anxiety. Journal of Behavior Therapy and Experimental Psychiatry, 12, 35-42.

Zitrin, C. M., Klein, D. F., \& Woerner, M. G. (1980). Treatment of agoraphobia with group exposure in vivo and imipramine. Archives of General Psychiatry, 37, 63-72. 